Scientific Journal of Silesian University of Technology. Series Transport Zeszyty Naukowe Politechniki Śląskiej. Seria Transport

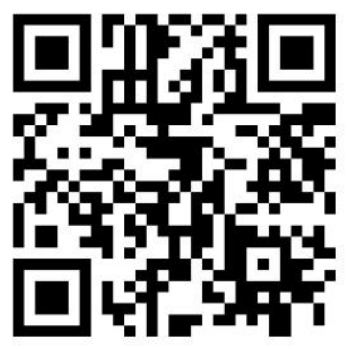

Volume 112

2021

p-ISSN: 0209-3324

e-ISSN: 2450-1549

DOI: https://doi.org/10.20858/sjsutst.2021.112.7

Journal homepage: http://sjsutst.polsl.pl

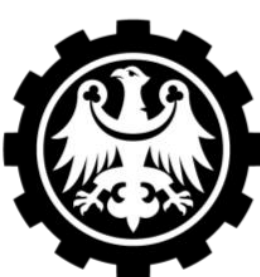

Silesian

University of Technology

Article citation information:

Kądziołka, T., Opoka, K. Forecasting the number of failures of the steering system components with the use of the grey system theory method. Scientific Journal of Silesian University of Technology. Series Transport. 2021, 112, 85-97. ISSN: 0209-3324.

DOI: https://doi.org/10.20858/sjsutst.2021.112.7.

Tomasz KĄDZIOLKA ${ }^{1}$, Kazimierz OPOKA ${ }^{2}$

\title{
FORECASTING THE NUMBER OF FAILURES OF THE STEERING SYSTEM COMPONENTS WITH THE USE OF THE GREY SYSTEM THEORY METHOD
}

Summary. Steering systems are one of the most important components of a car and have a direct impact on safety and driving comfort. Therefore, high reliability is required of them. One of the methods of object reliability estimation may be the grey system theory. This method can be used not only to calculate the number of failures, but also to calculate the wear of mating parts, and the vibrations of engines and rolling elements. This work presents the use of the grey system theory for the examination of motor vehicle steering system reliability. The forecast number of failures was calculated for the various components of the steering system and the grey system accuracy was assessed. This is aimed at finding out how useful this theory is for forecasting the number of steering system failures.

Keywords: steering mechanism, steering linkage, servo system, reliability, grey system theory method

\footnotetext{
${ }^{1}$ State University of Applied Sciences Nowy Sącz, Institute of Engineering, Zamenhofa 1A, 33-300 Nowy Sącz, Poland. Email: tkadziolka@pwsz-ns.edu.pl. ORCID: https://orcid.org/0000-0003-0877-0846

${ }^{2}$ State University of Applied Sciences Nowy Sącz, Institute of Engineering, Zamenhofa 1A, 33-300 Nowy Sącz, Poland. Email: kopoka@pwsz-ns.edu.pl. ORCID: https://orcid.org/0000-0002-3434-4827
} 


\section{INTRODUCTION}

Humans, in recent times, are being increasingly integrated with technology, becoming undoubtedly more dependent on technology. Consequently, with the development of technology, the demand for highly reliable and durable devices has increased because of their direct influence on safety.

The reliability theory in its field comprises the methods of failure forecasting, detection of the laws affecting defects and the development of ways of improving the reliability of objects. Forecasting object reliability is a crucial issue in present times. It enables one to foresee the states of the object in the future based on information on the states to have occurred already. Forecasting permits the determination of machine maintenance or inspection dates to ensure longer machine life and the operators' or travellers' safety when the means of transport are under discussion. Therefore, forecasting the future values of the symptoms of machinery technical condition is an issue of importance that has been widely discussed in reference literature $[3,17-20,25]$. One of the methods of object reliability assessment is the grey system theory. It was initiated and described by the Chinese scientist J.L. Deng in 1982 [5]. The theory is not only used in machine condition forecasting but also in economics [3]. This method can be used to calculate the number of failures, as well as to calculate the wear of mating parts, and the vibrations of engines and rolling elements.

This article aims to forecast the number of failures of the selected elements of the steering system of a selected motor vehicle using the aforementioned method.

\section{THE CHARACTERISTICS AND OPERATIONAL CONDITIONS OF STEERING SYSTEMS}

The steering system enables the driver to set, control and maintain the required direction of the vehicle movement by the appropriate alignment of the steered wheels. The steering system consists of three basic elements, that is, the steering mechanism, the steering linkage and the servo system. The steering mechanism consists of elements such as the steering wheel, steering column (the housing and articulated steering wheel shaft), steering gear and Pitman arm.

As mentioned above, the steering mechanism is used by the driver to set the steered wheels at such an angle that the vehicle moves in the designated direction. A typical steering system is shown in Figure 1 [7].

The steering wheel is made of a metal rod, polyurethane foam and fabric or leather. It is important to select the steering wheel diameter properly so that the force applied by the driver does not have to be too great. Generally, the steering wheel diameter ranges from 450 [mm] for cars and $550[\mathrm{~mm}]$ for trucks and buses. Through special catches, fitted by pressing, is the airbag assembly, placed in a plastic housing which usually functions as a horn actuator. In cars with automatic transmission, the steering wheel may have gear selection buttons; owing to them, the driver is not forced to take his or her hands off the steering wheel, thus, comfort and safety are improved.

The steering column is designed to transmit torque from the steering wheel to the steering gear. The steering column consists of a jacket attached to the vehicle body and of a bearingmounted steering wheel shaft. The shaft top end is completed with a multi-spline, which is designed for fixing the steering wheel, as well as with a thread for screwing the central clamp nut on. The steering wheel shaft can be made as one whole or it can be sectional, that is, consisting of two or three parts, connected by knuckle joints or multi-splines. 


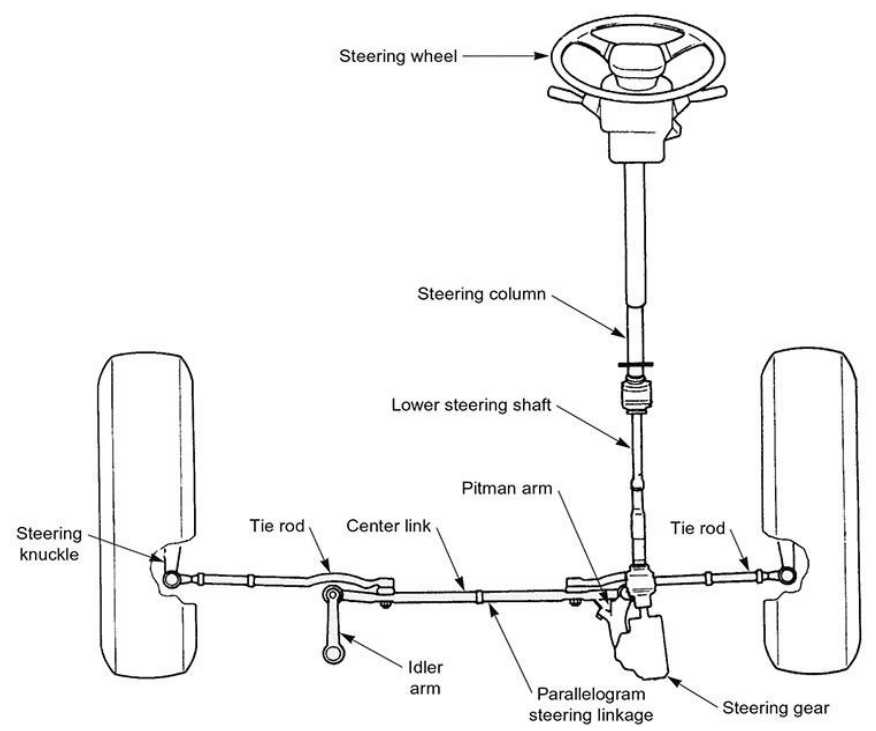

Fig. 1. The construction of the steering system [23]

The three-part steering wheel shaft consists of the upper and lower shafts connected with each other by pins, and the intermediate shaft. The lower intermediate shaft end, seated on a multi-spline, permits a change of its length, and the two knuckle joints permit the change of the torque transmission angle. A flexible joint is often placed between the lower end of the steering wheel shaft or of the intermediate shaft to compensate for small angular deviations and minimise vibrations transmitted to the steering wheel caused by driving on rough roads. The steering column is equipped with additional mechanisms; an energy absorption mechanism, steering wheel lock and adjustment mechanisms (steering wheel tilt or overhang) [7].

The steering gear is the main steering mechanism unit that acts as a reducer transmitting the rotary motion from the steering wheel to the steering linkage. The task of the steering gear is to ensure the appropriate kinematic and dynamic ratio so that the driver's effort is as low as possible.

Depending on the design details, transmission gears can be divided [7]: those providing the output rotary motion (worm and nut, globoid as well as ball and screw gear) and those providing the output translational motion (rack and pinion gear).

The steering linkage is a set of rods and levers connecting the steered wheels through the ball joints and Pitman arms. The task of the steering linkage is to achieve a kinematic connection, causing the vehicle wheels to move along a curvilinear track without skidding.

There are two types of steering linkage: one for the suspension with a rigid front axle and one for independent suspension. In the case of a rigid front axle, the steering linkage has a trapezoidal shape and a simple structure; however, such linkages are subject to a kinematics error. The independent suspension steering linkage should ensure the constant steered wheel toe-in during an independent movement of one of the steered wheels of the vehicle. The solution to this problem is the use of a central bar connecting the two side rods: the left and right one. The trapezoidal steering linkage with the steering gear providing output rotary motion comprises the following elements: the central rod, side rods (right and left); rod support; Pitman arms and stub axles (right and left).

In rack and pinion gears, the central rod is a toothed rack. The triangle-shaped steering linkage with rack and pinion gear comprises: side rods (right and left), Pitman arms and stab axles (right and left) [7]. 
The operation conditions to which the steering systems are subjected cause frequent failures of the components within it. The assessment of the technical condition of the steering system and the steering linkage pertains to the steering column and wheel, the steering gear and the condition of the steering rod ball joints.

The assessment is undertaken by checking the steering wheel lost motion and clearance in the steering mechanisms. Steering wheel lost motion is the result of excessive clearance in the steering system. Lost motion is assessed using the LUZ-1 instrument, permitting the measurement of the "idle" steering wheel rotation angle, which is the outcome of the total clearance of the entire system. The permissible value of the angle with the wheels set to drive straight ahead is $5-7^{\circ}$ in cars and $15-29^{\circ}$ in trucks.

The following should be included among the typical kinds of failure of the steering system:

- steering gear leakage,

- wear and tear of the mating elements of the steering gear,

- clearance in the ball joints of the rods,

- complete destruction of the ball joint (Figure 2),

- development of fatigue wear of cooperating elements.

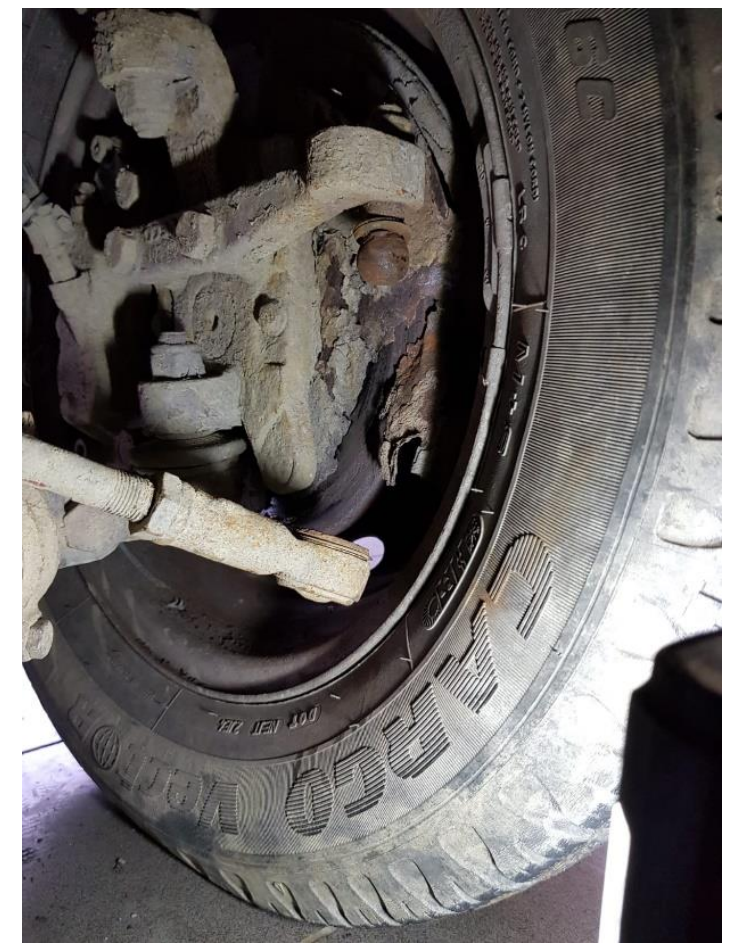

Fig. 2. An example of complete destruction of a ball joint

The damage to the elements shown in Figure 2 may be the result of the development of fretting wear. The condition for the development of this type of wear is the occurrence of oscillating tangential displacements between cooperating elements and the action of static forces $[10,13]$. Fretting wear occurs in many fields of technology and science. It is found, among others, in rail vehicles [11, 12], aircraft components [2], as well as biotechnology [4]. 


\section{RESEARCH METHODOLOGY}

Input data needed for the analysis was obtained from a database concerning the operation of a selected group of vehicles, and such has been collected over the last ten years by the car repair shop where the vehicles were serviced. Subject to analysis were the key elements of the steering system, such as the servo pump, steering gear and steering rod ends. These elements usually fail due to the condition of the road, and they directly influence travellers' safety.

By predicting the failure distribution trend, it is possible to determine the point at which the failure threshold rises rapidly, and thus, prevent the destruction of the system. This offers the option of ensuring system protection and travellers' safety, saving money.

\section{CHARACTERISTICS OF THE GREY SYSTEM THEORY}

The grey system theory is a relatively simple method as it does not require complicated calculations $[6,8,15,22,24]$. Generally, the very name "grey system" shows the nature of the method. It is an object's operational stage in which an amount of information (the number of failures) is known, and the other part is unknown.

The purely theoretical "grey system" theory model is determined by differential equation (1) $[1,11,24,26]$ :

$$
\frac{d X_{1}(t)}{d t}+a X_{1}(t)=u
$$

The variables such as " $a$ " and " $u$ " occurring in the equation are calculated using matrix operators from the following equations (2):

$$
\hat{a}=(a, u)^{T} ; \quad(a, u)^{T}=\left(B^{T} \cdot B\right)^{-1} \cdot B^{T} \cdot Y_{n}
$$

Parameters $B$ and $Y_{n}$ may be determined by solving matrices (3) and (4):

$$
\begin{aligned}
& B=\left[\begin{array}{cc}
-\left(X_{1}(1)+X_{1}(2)\right) \frac{1}{2} & 1 \\
-\left(X_{1}(2)+X_{1}(3)\right) \frac{1}{2} & 1 \\
\ldots & \\
-\left(X_{1}(n-1)+X_{1}(n)\right) \frac{1}{2} & 1
\end{array}\right] \\
& Y n=\left[\begin{array}{llll}
X_{0}(2) & X_{0}(3) & \ldots & X_{0}(n)
\end{array}\right]^{T}
\end{aligned}
$$

The matrices come into being from the model input data. The outcome of those mathematical operations is a two-line matrix $a x u$, which permits the determination of variables " $a$ " and " $u$ " which have been sought $[9,16]$.

The forecast values are calculated according to formula (5), which has come into being by appropriate transformations: 


$$
\hat{X}_{0}(t+1)=\left(\hat{X}_{0}(0)-u / a\right) \cdot e^{-a(t-1)} \cdot\left(e^{-a}-1\right)
$$

The determined parameters " $a$ " and " $u$ " are substituted into the formula in which the initial value $X(0)$ is equal to the first noted value.

The fact that the use of the method is reasonable may be determined by several formula transformations, and then, the result compared with the values from Table 1.

At the beginning, the remaining values are calculated based on formula (6).

$$
q(k)=X_{0}(k)-\hat{X}_{0}(k)
$$

Thereafter the arithmetic mean of the actual (noted) values is calculated with the use of formula (7).

$$
\bar{X}=\frac{1}{n} \sum_{k=1}^{n} X_{0}(k)
$$

The average of the remaining data $q(k)$ is determined based on formula (8).

$$
\bar{q}=\frac{1}{n} \sum_{k=1}^{n} q(k)
$$

Parameters $S_{1}$ and $S_{2}$, that is, the variances of the actual and remaining data are, in turn, determined based on formulae (9) and (10).

$$
\begin{gathered}
S_{1}^{2}=\frac{1}{n} \sum_{k=1}^{n}\left(X_{0}(k)-\bar{X}\right)^{2} \\
S_{2}^{2}=\frac{1}{n} \sum_{k=1}^{n}(q(k)-\bar{q})^{2}
\end{gathered}
$$

The quotient of the values obtained based on the formula above is equal to $C$ :

$$
\frac{S_{1}}{S_{2}}=C
$$

Now the method accuracy is checked by comparing the result with the values in Table 1 .

Tab. 1

The table permitting method accuracy determination

\begin{tabular}{|c|c|c|}
\hline Forecast accuracy & $P$ & \\
\hline Good & $>0.95$ & $<0.35$ \\
\hline Satisfactory & $0.8-0.9$ & $0.35-0.5$ \\
\hline Unsatisfactory & $0.7-0.8$ & $0.5-0.65$ \\
\hline Poor & $<0.7$ & $>0.65$ \\
\hline
\end{tabular}




\section{FORECAST OF THE NUMBER OF FAILURES OF THE SELECTED STEERING SYSTEM COMPONENTS}

\subsection{Steering gear}

Input data in the form of the number of the noted steering gear failures for specific mileage are collated in Table 2. Fifteen time intervals within 15,000-225,000 km have been indicated, in which the input data is noted in the form of the number of recorded failures of the ten vehicles under observation. The number of failures within the other five time intervals, that is, from $240,000 \mathrm{~km}$ to $310,000 \mathrm{~km}$, are estimated based on the analysis.

Tab. 2

Schedule of input data

\begin{tabular}{|c|c|c|c|c|c|c|c|c|c|c|}
\hline Measurement & 1 & 2 & 3 & 4 & 5 & 6 & 7 & 8 & 9 & 10 \\
\hline Mileage $[\mathrm{km}]$ & 15000 & 30000 & 45000 & 60000 & 75000 & 90000 & 105000 & 120000 & 135000 & 150000 \\
\hline$A$ & 35 & 37 & 41 & 49 & 56 & 69 & 77 & 85 & 93 & 101 \\
\hline
\end{tabular}

\begin{tabular}{|c|c|c|c|c|c|c|c|c|c|c|}
\hline Measurement & 11 & 12 & 13 & 14 & 15 & 16 & 17 & 18 & 19 & 20 \\
\hline Mileage $[\mathrm{km}]$ & 165000 & 180000 & 195000 & 210000 & 225000 & 240000 & 265000 & 280000 & 295000 & 310000 \\
\hline$A$ & 113 & 129 & 134 & 141 & 160 & - & - & - & - & - \\
\hline
\end{tabular}

$A$ - number of failures noted $X_{0}(i)$

With the use of formulae (1)-(4), parameters $B$ and $Y_{n}$ were first determined, then parameters $a$ and $u$ needed for the estimation of the number of failures were calculated.

$$
\begin{gathered}
=\left[\begin{array}{cccccccccccccc}
1 & 1 & 1 & 1 & 1 & 1 & 1 & 1 & 1 & 1 & 1 & 1 & 1 & 1 \\
-53.5 & -92.5 & -137.5 & -190 & -252.5 & -325.5 & -406.5 & -496.5 & -592.5 & -699.5 & -820.5 & -952 & -1089.5 & -1240
\end{array}\right]^{T} \\
\quad Y_{n}=
\end{gathered}
$$

The values of parameters $a$ and $u$, respectively, are as follows:

$$
\begin{aligned}
& a=-0,101378 \\
& u=38,58057
\end{aligned}
$$

When all the unknown quantities are already known, the forecast number of steering gear failures may be determined based on formula (5). The results of those calculations are compiled in Table 3. The comparison of the number of failures noted with the forecast number is shown in Figure 3.

The next stage of the calculations is the determination of method accuracy. Formulas (6)(11) will be used for this purpose. Parameter $C$ has been determined, which will be compared with Table 1 . The obtained result is $C=0.121725$, which confirms that method accuracy is at a good level. 
Tab. 3

Forecast number of steering gear failures

\begin{tabular}{|c|c|c|c|c|c|c|c|c|c|}
\hline $\mathrm{X}^{\prime} 0(1)$ & $\mathrm{X}^{\prime} 0(2)$ & $\mathrm{X}^{\prime} 0(3)$ & $\mathrm{X}^{\prime} 0(4)$ & $\mathrm{X}^{\prime} 0(5)$ & $\mathrm{X}^{\prime} 0(6)$ & $\mathrm{X}^{\prime} 0(7)$ & $\mathrm{X}^{\prime} 0(8)$ & $\mathrm{X}^{\prime} 0(9)$ & $\mathrm{X}^{\prime} 0(10)$ \\
\hline 35 & 44.33 & 49.06 & 54.30 & 60.09 & 66.51 & 73.60 & 81.46 & 90.15 & 99.77 \\
\hline
\end{tabular}

\begin{tabular}{|c|c|c|c|c|c|c|c|c|c|}
\hline $\mathrm{X}^{\prime} 0(11)$ & $\mathrm{X}^{\prime} 0(12)$ & $\mathrm{X}^{\prime} 0(13)$ & $\mathrm{X}^{\prime} 0(14)$ & $\mathrm{X}^{\prime} 0(15)$ & $\mathrm{X}^{\prime} 0(16)$ & $\mathrm{X}^{\prime} 0(17)$ & $\mathrm{X}^{\prime} 0(18)$ & $\mathrm{X}^{\prime} 0(19)$ & $\mathrm{X}^{\prime} 0(20)$ \\
\hline 110.41 & 122.19 & 135.23 & 149.66 & 165.63 & 183.30 & 202.85 & 224.50 & 248.45 & 274.96 \\
\hline
\end{tabular}

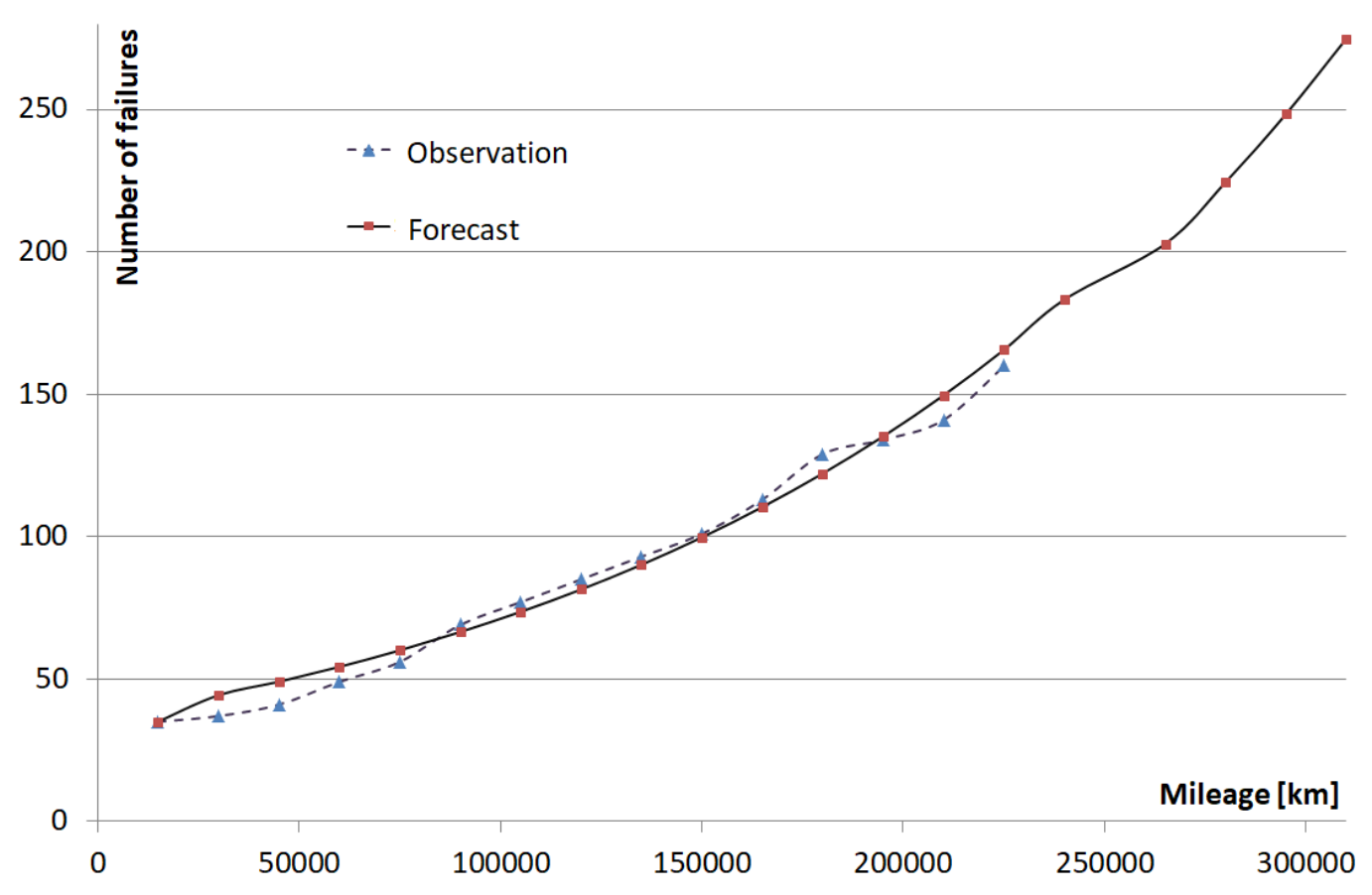

Fig. 3. The distribution of the noted and estimated number of steering gear failures

\subsection{Steering rod ends}

Input data in the form of the number of the noted steering gear failures for specific mileage are collated in Table 4. As in the previous case, fifteen time intervals within 15,000-225,000 $\mathrm{km}$ were indicated, in which the input data is noted in the form of the number of recorded failures of the ten vehicles under observation. The number of failures within the other five time intervals, that is, from $240,000 \mathrm{~km}$ to $310,000 \mathrm{~km}$, are estimated based on the analysis.

Tab. 4

Schedule of initial values and mileage

\begin{tabular}{|c|c|c|c|c|c|c|c|c|c|c|}
\hline Measurement & 1 & 2 & 3 & 4 & 5 & 6 & 7 & 8 & 9 & 10 \\
\hline Mileage $[\mathrm{km}]$ & 15000 & 30000 & 45000 & 60000 & 75000 & 90000 & 105000 & 120000 & 135000 & 150000 \\
\hline$A$ & 45 & 48 & 50 & 61 & 73 & 86 & 94 & 101 & 115 & 124 \\
\hline
\end{tabular}




\begin{tabular}{|c|c|c|c|c|c|c|c|c|c|c|}
\hline Measurement & 11 & 12 & 13 & 14 & 15 & 16 & 17 & 18 & 19 & 20 \\
\hline Mileage $[\mathrm{km}]$ & 165000 & 180000 & 195000 & 210000 & 225000 & 240000 & 265000 & 280000 & 295000 & 310000 \\
\hline$A$ & 136 & 148 & 159 & 166 & 172 & - & - & - & - & - \\
\hline
\end{tabular}

$A$ - the number of noted failures $X_{O}(i)$

With the use of formulas (1)-(4), parameters $B$ and $Y_{n}$ were first determined, then parameters $a$ and $u$ needed for the estimation of the number of failures were calculated.

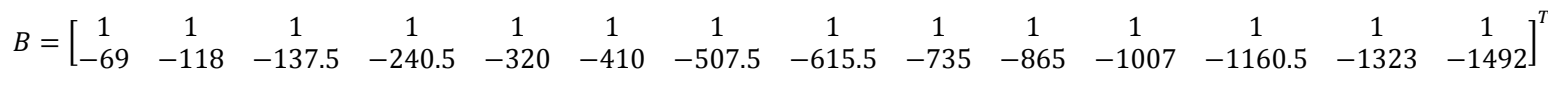

$$
\begin{aligned}
& Y_{n}=\left[\begin{array}{llllllllllllll}
48 & 52 & 62 & 73 & 86 & 94 & 101 & 115 & 124 & 136 & 149 & 159 & 166 & 172
\end{array}\right]^{T}
\end{aligned}
$$

The values of parameters $a$ and $u$, respectively, are as follows:

$$
\begin{aligned}
& a=-0.0907 \\
& u=50.96
\end{aligned}
$$

When all the unknown quantities are already known, the forecast number of failures of steering rod ends may be determined based on formula (5). The results of the calculations are compiled in Table 5. The comparison of the number of failures noted with the forecast number is shown in Figure 4.

Tab. 5

Forecast numbers of steering rod end failures

\begin{tabular}{|c|c|c|c|c|c|c|c|c|c|}
\hline $\mathrm{X}^{\prime} 0(1)$ & $\mathrm{X}^{\prime} 0(2)$ & $\mathrm{X}^{\prime} 0(3)$ & $\mathrm{X}^{\prime} 0(4)$ & $\mathrm{X}^{\prime} 0(5)$ & $\mathrm{X}^{\prime} 0(6)$ & $\mathrm{X}^{\prime} 0(7)$ & $\mathrm{X}^{\prime} 0(8)$ & $\mathrm{X}^{\prime} 0(9)$ & $\mathrm{X}^{\prime} 0(10)$ \\
\hline 45 & 57.61 & 63.08 & 69.07 & 75.62 & 82.80 & 90.67 & 99.27 & 108.70 & 119.02 \\
\hline
\end{tabular}

\begin{tabular}{|c|c|c|c|c|c|c|c|c|c|}
\hline $\mathrm{X}^{\prime} 0(11)$ & $\mathrm{X}^{\prime} 0(12)$ & $\mathrm{X}^{\prime} 0(13)$ & $\mathrm{X}^{\prime} 0(14)$ & $\mathrm{X}^{\prime} 0(15)$ & $\mathrm{X}^{\prime} 0(16)$ & $\mathrm{X}^{\prime} 0(17)$ & $\mathrm{X}^{\prime} 0(18)$ & $\mathrm{X}^{\prime} 0(19)$ & $\mathrm{X}^{\prime} 0(20)$ \\
\hline 130.32 & 142.69 & 156.24 & 171.07 & 187.31 & 205.10 & 224.57 & 245.89 & 269.23 & 294.79 \\
\hline
\end{tabular}

The next stage of the calculations is the determination of method accuracy. Formulas (6)(11) will be used for this purpose. Parameter $C$ has been determined, which will be compared with Table 1 . The obtained result is $C=0.161643$, which confirms that method accuracy is at a good level.

\subsection{Servo pump}

Input data in the form of the number of the noted servo pump failures for specific mileage are collated in Table 6 . In this case, fifteen time intervals within 15,000-225,000 km have been indicated as well, in which the input data is noted in the form of the number of recorded failures of the ten vehicles under observation. The number of failures within the other five time intervals, that is, from $240,000 \mathrm{~km}$ to $310,000 \mathrm{~km}$, are estimated based on the analysis. 


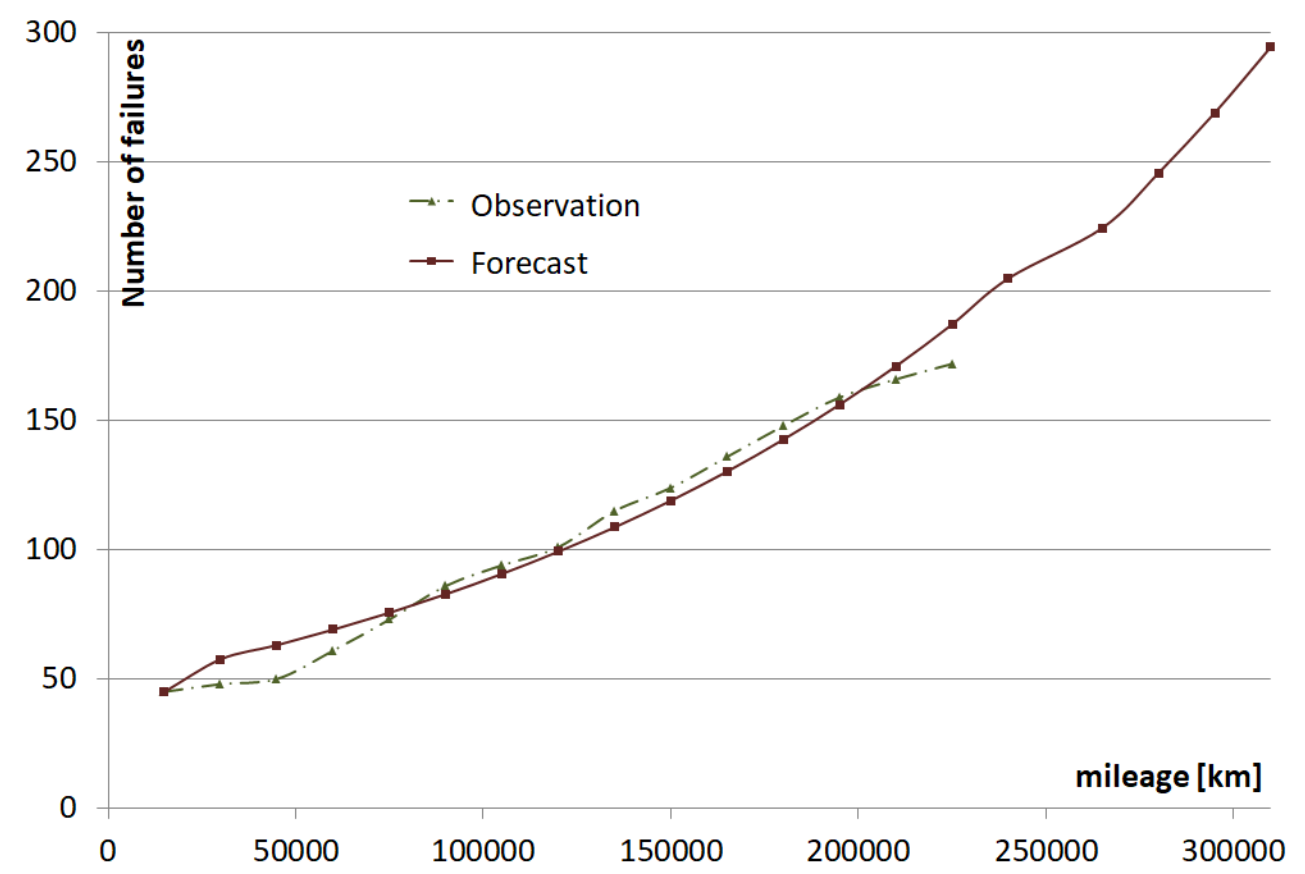

Fig. 4. The distribution of the noted and estimated number of steering rod end failures

Tab. 6

Schedule of initial values and mileage

\begin{tabular}{|c|c|c|c|c|c|c|c|c|c|c|}
\hline Measurement & 1 & 2 & 3 & 4 & 5 & 6 & 7 & 8 & 9 & 10 \\
\hline Mileage $[\mathrm{km}]$ & 15000 & 30000 & 45000 & 60000 & 75000 & 90000 & 105000 & 120000 & 135000 & 150000 \\
\hline$A$ & 20 & 28 & 37 & 44 & 56 & 62 & 69 & 73 & 81 & 90 \\
\hline
\end{tabular}

\begin{tabular}{|c|c|c|c|c|c|c|c|c|c|c|}
\hline Measurement & 11 & 12 & 13 & 14 & 15 & 16 & 17 & 18 & 19 & 20 \\
\hline Mileage $[\mathrm{km}]$ & 165000 & 180000 & 195000 & 210000 & 225000 & 240000 & 265000 & 280000 & 295000 & 310000 \\
\hline$A$ & 96 & 107 & 110 & 115 & 121 & - & - & - & - & - \\
\hline
\end{tabular}

$A-$ the number of noted failures $X_{0}(i)$

With the use of formulae (1)-(4), parameters $B$ and $Y_{n}$ were first determined, then parameters $a$ and $u$ needed for the estimation of the number of failures were calculated.

$$
\begin{gathered}
B=\left[\begin{array}{cccccccccccccc}
1 & 1 & 1 & 1 & 1 & 1 & 1 & 1 & 1 & 1 & 1 & 1 & 1 & 1 \\
-34 & -66.5 & -107 & -157 & -216 & -281.5 & -352.5 & -429.5 & -515 & -608 & -709.5 & -818 & -930.5 & -1048.5
\end{array}\right]^{T} \\
Y_{n}=\left[\begin{array}{llllllllllllll}
28 & 37 & 44 & 56 & 62 & 69 & 73 & 81 & 90 & 96 & 107 & 110 & 115 & 121
\end{array}\right]^{T}
\end{gathered}
$$

In this case, the values of parameters $a$ and $u$, respectively, are as follows:

$a=-0.08816$

$u=38.27891$ 
When all the unknown quantities are already known, the forecast number of servo pump failures may be determined based on formula (5). The results of the calculations are compiled in Table 7. The comparison of the number of failures noted with the forecast number is shown in Figure 5.

Tab. 7

Schedule of initial values and mileage

\begin{tabular}{|c|c|c|c|c|c|c|c|c|c|}
\hline $\mathrm{X}^{\prime} 0(1)$ & $\mathrm{X}^{\prime} 0(2)$ & $\mathrm{X}^{\prime} 0(3)$ & $\mathrm{X}^{\prime} 0(4)$ & $\mathrm{X}^{\prime} 0(5)$ & $\mathrm{X}^{\prime} 0(6)$ & $\mathrm{X}^{\prime} 0(7)$ & $\mathrm{X}^{\prime} 0(8)$ & $\mathrm{X}^{\prime} 0(9)$ & $\mathrm{X}^{\prime} 0(10)$ \\
\hline 20 & 41.86 & 45.71 & 49.93 & 54.53 & 59.56 & 65.05 & 71.04 & 77.59 & 84.74 \\
\hline
\end{tabular}

\begin{tabular}{|c|c|c|c|c|c|c|c|c|c|}
\hline $\mathrm{X}^{\prime} 0(11)$ & $\mathrm{X}^{\prime} 0(12)$ & $\mathrm{X}^{\prime} 0(13)$ & $\mathrm{X}^{\prime} 0(14)$ & $\mathrm{X}^{\prime} 0(15)$ & $\mathrm{X}^{\prime} 0(16)$ & $\mathrm{X}^{\prime} 0(17)$ & $\mathrm{X}^{\prime} 0(18)$ & $\mathrm{X}^{\prime} 0(19)$ & $\mathrm{X}^{\prime} 0(20)$ \\
\hline 92.55 & 101.08 & 110.40 & 120.57 & 131.69 & 143.82 & 157.08 & 171.56 & 187.37 & 204.64 \\
\hline
\end{tabular}

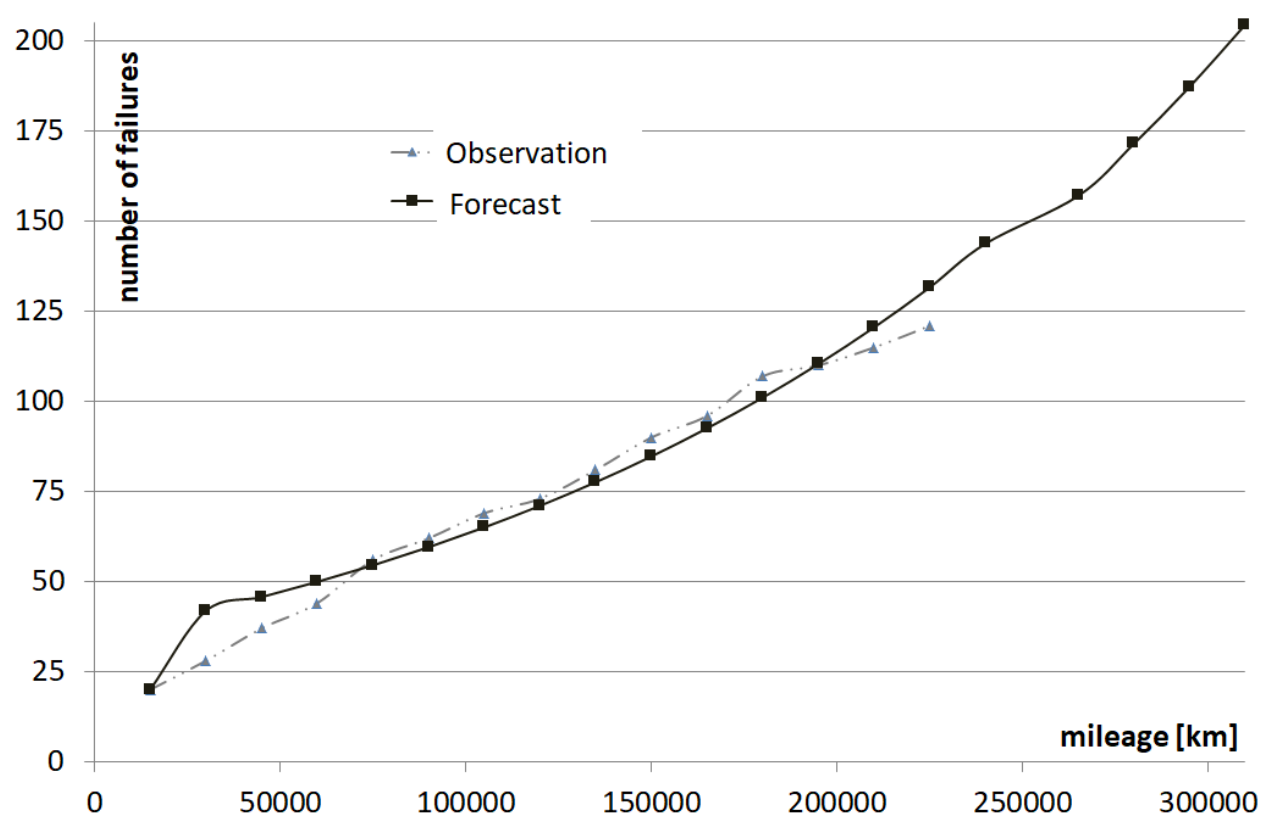

Fig. 5. The distribution of the noted and estimated number of servo pump failures

The next stage of the calculations is the determination of method accuracy. Formulas (6)(11) are used for this purpose. Parameter $C$ has been determined, which will be compared with Table 1 . The obtained result is $C=0.191000$, which confirms that method accuracy is at a good level.

\section{CONCLUSION}

The analysis aimed to assess the possible number of selected steering system component failures that may occur as mileage increases.

Based on the method accuracy determination results, it may be believed that the grey system analysis proposed in this article is suitable for forecasting the number of steering system failures. 
Moreover, system efficiency decreases with the distance covered by vehicles. The question is about the number of the recorded failures, which permits the relevant inspection cycles for the vehicles under analysis to be designed. Based on the forecast, the number of possible system failures increases proportionally. After covering $300,000 \mathrm{~km}, 275$ various steering gear failures, 295 steering rod failures and 205 servo pump failures should be expected.

The considerations contained in the paper allows, among other things, to increase road safety by forecasting possible damage to the steering systems and repairing them in advance, before their complete destruction (Figure 2). By analogous considerations, it is possible to predict damage to other mechanisms or systems used not only in motor vehicles (braking system, drive system, power-running system, drive unit) but also in working machines as they can be used to predict their failure-free time operation and precisely define the intervals between maintenance and repair.

\section{References}

1. Bezuglov Anton, Gurcan Comert. 2016. „Short-term freeway traffic parameter prediction: Application of grey system theory models". Expert Systems With Applications 62: 284-292.

2. Bok-WonLee, Jungjun Suh, Hongchu Lee, Tae-gu Kim. 2011. „Investigations on fretting fatigue in aircraft engine compressor blade". Engineering Failure Analysis 18 (7): 1900-1908.

3. Cempel Czesław, Maciej Tabaszewski. 2007. „Application of grey system theory to modeling and forecasting in machine condition monitoring”. Diagnostyka 2(42): 11-18.

4. Chen-EnTsa, Jiames Hung, Youxin Hu, Da-Yung Wang, Robert M.Pilliar, Rizhi Wang. 2021. „Improving fretting corrosion resistance of CoCrMo alloy with TiSiN and ZrN coatings for orthopedic applications". Journal of the Mechanical Behavior of Biomedical Materials 114: 104233.

5. Deng J-L. 1982. „Control Problems of Grey Systems”. Systems and Control Letters 1(5): 288-294.

6. Deng Julong. 1989. „Introduction to Grey System Theory”. The Journal of Grey System 1: $1-24$.

7. Gabryelewicz M. 2011. Podwozia i nadwozia pojazdów samochodowych. [In Polish: Chassis and bodies of motor vehicles]. Part 2. Warsaw: WKiŁ. ISBN: 9788320618266.

8. Jui-Chen Huang. 2011. „Application of grey system theory in telecare”. Computers in Biology and Medicine 41(5): 302-306.

9. Kayacan Erdal, Ulutas Baris, Kaynak Okyay. 2010. „Grey system theory-based models in time series prediction”. Expert Systems with Applications 37 (2): 1784-1789.

10. Kowalski Sławomir. 2018. „Analysis of the possibilities of using CrN+a-C:H:W coatings to mitigate fretting wear in push fit joints operating in rotational bending conditions". Tribologia 1: 45-55.

11. Kowalski Sławomir. 2016. „Application of dimensional analysis in the fretting wear studies". Journal of the Balkan Tribological Association 22(4-I): 3823-3835.

12. Kowalski Sławomir. 2020. „Failure analysis of the elements of a forced-in joint operating in rotational bending conditions". Engineering Failure Analysis 118: 104864.

13. Kowalski Sławomir. 2017. „Selected problems in the exploitation of wheel sets in rail vehicles". Journal of Machine Construction and Maintenance 2: 109-116. 
14. Kowalski Sławomir, Mariusz Cygnar. 2019. „The application of TiSiN/TiAlN coatings in the mitigation of fretting wear in push fit joints". Wear 426: 725-734.

15. Li-Qiang Hu, Chao-Feng He, Zhao-Quan Cai, Long Wen, Teng Ren. 2018. „Track circuit fault prediction method based on grey theory and expert system". J. Vis. Commun. Image R. 58: 37-45.

16. Liu Sifeng. 2007. „The Current Developing Status on Grey System Theory” The Journal of Grey System 2: 111-123.

17. Maláková Silvia, Peter Frankovský, Daniela Harachová, Vojtech Neumann. 2019. „Design of constructional optimisation determined for mixed truck gearbox". AD ALTA Journal of Interdisciplinary Research 9: 414-417. ISSN: 1804-7890.

18. Maláková Silvia, Michal Puškár, Peter Frankovský, Samuel Sivák, Maroš Palko, Miroslav Palko. 2020. „Meshing Stiffness - A Parameter Affecting the Emission of Gearboxes". Applied Sciences 10(3): 1-12. DOI: 10.3390/app10238678.

19. Mazurkiewicz D. 2014. „Computer-aided maintenance and reliability management systems for conveyor belts". Eksploatacja i Niezawodnosc-Maintenance and Reliability 16(3): 377-382.

20. Michalski R., S. Wierzbicki. 2008. „An analysis of degradation of vehicles in operation”. Eksploatacja i Niezawodnosc-Maintenance and Reliability 1: 30-32.

21. Mu-Shang Yin. 2013. „Fifteen years of grey system theory research: A historical review and bibliometric analysis". Expert Systems with Applications 40: 2767-2775.

22. Shuwei Wanga, Peng Wanga, Yifei Zhang. 2020. „A prediction method for urban heat supply based on grey system theory". Sustainable Cities and Society 52: 101819.

23. Steering and suspancion components. Available at: https://en.tw-central.com.

24. Tabaszewski Maciej. 2014. "Prediction of diagnostic symptom values using a set of models GM(1,1) and a moving window method". Diagnostyka 15(3): 65-68.

25. Vaičekauskis M., R. Gaidys, V. Ostaševičius. 2013. „Influence of boundary conditions on the vibration modes of the smart turning tool". Mechanika 3: 296-300.

26. Xingqi Wang, Lei Qi, Chan Chen, Jingfan Tang, Ming Jiang. 2014. „Grey System Theory based prediction for topic trend on Internet". Engineering Applications of Artificial Intelligence 29: 191-200.

Received 07.04.2021; accepted in revised form 23.06.2021

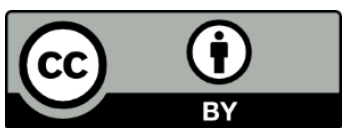

Scientific Journal of Silesian University of Technology. Series Transport is licensed under a Creative Commons Attribution 4.0 International License 